\title{
The conformational polymorphism of 1,1,2,2-tetrachloroehtane $\left(\mathrm{C}_{2} \mathrm{H}_{2} \mathrm{Cl}_{4}\right)$
}

\author{
Ph. Negrier ${ }^{1}$, M. Barrio+, M. Zuriaga ${ }^{3}$, S.C. Pérez ${ }^{3}$, J.Ll. Tamarit ${ }^{2}$, and D. Mondieig ${ }^{1}$ \\ ${ }^{1}$ Laboratoire Ondes et Matière d'Aquitaine, UMR 5798 au CNRS-Université Bordeaux I, 351, cours de la Libération, 33405 \\ Talence Cedex, France. \\ ${ }^{2}$ Grup de Caracterització de Materials, Department de Física I Enginyeria Nuclear, ETSEIB, Diagonal 647, 08028 Barcelona, \\ Universitat Politècnica de Catalunya, Catalonia \\ ${ }^{3}$ Facultad de Matemática, Astronomía y Física, Universidad Nacional de Córdoba and IFEG-CONICET, Ciudad \\ Universitaria, X5016LAE Córdoba, Argentina
}

The molecule of 1,1,2,2-tetrachloroethane can appear in two different conformations: trans (antiperiplanar) and gauche (synclinal). The slight energy difference between both conformers $\left(<1 \mathrm{kcal} \mathrm{mol}^{-1}\right)[1,2]$ means that the polymorphic phases appearing at different temperature and pressure conditions would mainly depend on the intermolecular interactions.

At normal pressure, the stable phase $\beta$ is known to be orthorhombic ( $\left.\mathrm{P} 22_{1} 2_{1} 2_{1}, \mathrm{Z}=8, \mathrm{Z}^{\prime}=2\right)$ with only one gauche conformation. At high-pressure (ca. $0.65 \mathrm{GPa}$ ) the structure of a second polymorph was found to be monoclinic $\left(\mathrm{P} 2{ }_{1} / \mathrm{c}\right.$, $\mathrm{Z}=2, \mathrm{Z}^{\prime}=0.5$ ) and formed by only molecules with trans conformation [3].

The present work presents a new solid phase in which both gauche conformers coexist. This phase is reached by means of recrystallization of the supercooled melt into a new metastable $\alpha$, phase, which on heating transforms irreversibly to the stable $\beta$ phase. The thermodynamic relationships between the different condensed phases as well as the structural details of the new phase will be detailed in the present communication.

\section{References}

1. J.E. Mark, C. Sutton, J. Am. Chem. Soc. 94, 1083 (1972)

2. (a) J.R. Thomas and W. D. Gwinn, J. Am. Chem. Soc. 71, 2785 (1949)

(b) R.J. Abraham, K. Parry, Chem. Commun. 963 (1969)

(c) R.J. Abraham, K. Parry, J. Chem. Soc. B 539 (1970)

3. M. Bujak, D. Bläser, A. Katrusiak, R. Boese, Chem. Commun. 47, 8769-8771 (2011) 